Lena Hansson har en gymnasielärarutbildning och har arbetat som gymnasielärare i fysik och matematik. Hon är nu doktorand i naturvetenskapernas didaktik på Högskolan Kristianstad, Sverige. Hon är också en av doktoranderna i den svenska nationella forskarskolan i naturvetenskapernas och teknikens didaktik (FontD). Hennes forskningsintresse handlar om vilken typ av världsbilder som eleverna förknippar med naturvetenskapen och möjliga konsekvenser av detta för undervisning och lärande.

Britt Lindahl är lektor i ämnesdidaktik på Högskolan Kristianstad, Sverige. Hon undervisar där i naturvetenskap för lärarstuderande och för lärare som arbetar med grundskolans tidigare år. Hennes avhandling var en longitudinell studie från år 5 och vidare genom grundskolan om sambandet mellan elevers intresse, förståelse, förmåga och deras val av studieinriktning på gymnasiet. Hon arbetar nu med projekt om hur skolans undervisning påverkar elevers attityder till och lust att lära naturvetenskap.

\title{
LENA HANSSON
}

FontD och Högskolan Kristianstad, Sverige

e-post: lena.hansson@hkr.se

\section{BRITT LINDAHL}

\section{Apropå Fuglesang Världsbilder och rekryteringen till naturveten- skapliga/tekniska utbildningar}

\author{
Abstract \\ In connection to the astronaut Christer Fuglesang's space flight, different stakeholders have expressed \\ a hope that this event will increase the interest among youths for science and technology studies. \\ The modernistic and technique positive discourse that is used is however not unproblematic in this \\ situation. In the article this is exemplified with students' views concerning the possibility that humans \\ in the future will be able to live on other planets. This is something that, during an interview, was \\ mentioned by Fuglesang as the main reason for space flights.
}

Reporter: Om du möter en skeptiker vad är ditt bästa argument för att övertyga om att det är värt pengarna att ta sig upp i rymden?

Fuglesang: Ja, för mig är det viktigaste - det är den här visionen att vi som människor en gång ska åka ut i rymden och inte bara bo på jorden utan kunna bosätta oss på andra himlakroppar. Reporter: Ska vi det?

Fuglesang: Ja, det ska vi.

Reporter: Jaha.

Fuglesang: Liksom för 500 år sen när européer började flytta över till Amerika och bosätta sig där så ser jag att om ett antal hundra år hur vi kan bosätta oss på Mars och utnyttja resurserna där för att liksom leva på dem.

Reporter: När vi har förbrukat jorden?

Fuglesang: Nej, vi ska inte förbruka jorden, men jag menar vi ska utöka antalet världar som vi kan bo på. Och det är klart att det är en försäkring om någonting går riktigt illa, att vi kan bo på andra ställen också. 
Många aktörer i samhället ser idag med stor oro på bristen på intresse bland ungdomar för naturvetenskap och teknik samt tendensen att välja bort naturvetenskapliga och tekniska inriktningar på olika nivåer i utbildningssystemet (EU, 2004). Till exempel har den svenska regeringen under 10 år satsat pengar på NOT ${ }^{1}$-projektet och EU satsar på många olika projekt inom "Science and Society" (EU, 2005). Alla har som syfte att på olika sätt öka intresset för naturvetenskap/teknik och naturvetenskapliga/tekniska studier. Eftersom universum i alla tider intresserat människor, så kan man förstå förhoppningen att den förste svenske astronautens rymdresa ska tjäna samma syfte. T.ex. uttryckte svenska regeringsrepresentanter i samband med rymdresan förhoppningen att Christer Fuglesang skulle bli en förebild och att resan skulle leda till ett ökat intresse för naturvetenskap och teknik hos ungdomar. Observeras bör att det naturligtvis inte är självklart att ett intresse för naturvetenskap/teknik leder till att ungdomar faktiskt väljer naturvetenskapliga/ tekniska studier. Många faktorer spelar in vid utbildningsval (Lindahl, 2003; Lyons, 2006). Det är dock troligt att positivt intresse för naturvetenskap/teknik ökar sannolikheten för att individen väljer en sådan utbildningsväg.

När man försöker intressera människor för naturvetenskap sätts naturvetenskapen ofta in i ett sammanhang som förutsätter specifika ideologier/världsbilder. Begreppen världsbild och ideologi används ibland på liknande sätt och ibland med olika skillnader. I den här artikeln syftar vi när vi talar om världsbild på ontologiska synsätt - hur världen är beskaffad, medan vi med ideologi syftar på synsätt kopplade till samhällsfrågor, d.v.s. politiska synsätt. Fourez (1988) är tidig inom det naturvetenskapliga didaktiska forskningsfältet med att diskutera ideologier i samband med naturvetenskaplig undervisning. Han hävdar att naturvetenskap inte kan presenteras ideologineutralt, men att problemet inte är att naturvetenskapen syns tillsammans med specifika ideologier/ världsbilder utan istället den omedvetenhet som råder om detta förhållande. Ideologier/världsbilder kan uttryckas explicit, men vanligt är också att de uttrycks implicit, i form av följemeningar (Östman, 1995; Roberts, 1998).

Beroende av vilken ideologi/världsbild som tas för given när naturvetenskap presenteras blir förutsättningarna olika för att en individ ska attraheras av naturvetenskapen. För individer med ideologier/världsbilder som skiljer sig från den som förutsätts, blir det svårare att identifiera sig med naturvetenskapen, medan det blir enklare för individer med en ideologi/världsbild som liknar den som naturvetenskapen presenteras tillsammans med. Hur individer på grund av olika ideologier/världsbilder kan reagera väldigt olika på ett scenario som skulle kunna tänkas vara intresseväckande kommer här att illustreras. Detta görs med hjälp av exempel där olika elever resonerar kring visionen att människor i framtiden skulle bosätta sig på planeten Mars. Det är just denna vision som används ovan av Fuglesang för att intressera människor för - och övertyga dem om vikten av - rymdresor.

Det finns forskare, som i likhet med Fuglesang ovan, funderar över huruvida människor skulle kunna leva permanent på någon annan planet i framtiden. Den planet som i första hand har förts fram som en lämplig kandidat i de här diskussionerna är just Mars. För att människor skulle kunna bo på Mars krävs att man tranformerar planeten så att villkoren där blir mer lika dem på jorden. Detta skulle kräva omfattande insatser och idag är det inte tekniskt möjligt. Man hoppas dock att naturvetenskapliga och tekniska framgångar ska leda till att detta i framtiden ska kunna genomföras. Det är denna vision som Fuglesang, på en fråga om hur han vill övertyga den skeptiske om det vettiga i rymdfärder, för fram som sitt främsta argument (se ovan). Är detta en vision som delas av ungdomar idag och därför något som kan antas öka intresset för naturvetenskap och teknik? Det är detta som vi här vill belysa.

${ }^{1}$ NOT-projektet avslutades 2005. Mer information finns att söka på http://www.skolutveckling.se 


\section{TEORETISK RAM}

Den här artikeln är en del av rapporteringen från ett större projekt där vi intresserar oss för sambandet mellan elevers intresse/brist på intresse för naturvetenskap och i vilken mån elevernas egna grundantaganden om världen överensstämmer med dem som de förknippar med naturvetenskapen (Hansson \& Lindahl, 2007). I projektet utgår vi från att intresse är kopplat till de grundantaganden om världen som individen gör (Cobern, 1991). Utifrån detta synsätt utgör grundantaganden (Cobern, 1991; Cobern, 1996) en utgångspunkt för hur individen förstår och tänker kring fenomen, modeller och frågeställningar som hon eller han möter:

"Worldview provides a nonrational foundation for thought, emotion, and behaviour. Worldview provides a person with presuppositions about what the world is really like and what constitutes valid and important knowledge about the world" (Cobern, 1996, s. 584)

Sådana grundantaganden kan handla t.ex. om hur man ser på huruvida det finns en gud eller högre makt och hur relationen mellan denna och den materiella världen ser ut, hur man ser på relationen mellan människa och natur, synsätt på huruvida det finns någon mening med vår existens o.s.v. (se vidare Hansson \& Redfors, 2007b).

I de flesta fall handlar den oro som uttrycks vad gäller ungdomars bristande intresse för naturvetenskapliga/tekniska utbildningar framför allt om antalet elever/studenter som väljer sådana utbildningar. Stenmark (2004) tar upp en annan aspekt som vi vill anknyta till här. Han menar att eftersom naturvetenskaplig forskning inte är världsbilds- eller ideologineutral så är det viktigt att vara uppmärksam på vilka ideologier som finns, respektive inte finns, representerade i forskningens olika faser. Det är önskvärt (Stenmark, 2004) att

"the scientific community consists of people with different ideological or religious backgrounds so that the research topics undertaken and the questions asked reflect the interests of different groups of people" (p. 220-221).

Det blir då viktigt att ungdomar får se exempel på att människor med olika ideologier och världsbilder arbetar med naturvetenskaplig forskning (Stenmark, 2004). Detta skulle göra det enklare för elever med olika världsbilder och ideologier att identifiera sig med naturvetenskapen.

Ovanstående är relaterat till de författare som hävdar att lära naturvetenskap handlar om mer än att förstå (t.ex. Cobern, 1996; Brickhouse, 2001; Lemke, 2001). Brickhouse skriver att naturvetenskaplig utbildning också måste förstås som en identitetsskapande process: "We need to know how students engage in science and how this is related to who they are and who they want to be" (s. 286). Huruvida en person vill ta del av naturvetenskaplig undervisning beror alltså delvis på hur eleven ser på naturvetenskap i relation till den person hon/han själv vill vara. För vårt projekt blir det här relevant om en individ förknippar naturvetenskapen med specifika världsbilder och ideologier som hon eller han själv inte delar. Om naturvetenskapen förknippas med en specifik världsbild eller ideologi, finns det en risk att detta leder till att de grupper av elever som inte delar denna väljer bort naturvetenskapliga studier. Om detta inträffar får vi en exkludering av individer, så väl som av ideologier/världsbilder.

\section{DESIGN AV STUDIEN}

Den här studien är ett samarbete mellan två forskningsprojekt. Den första författaren arbetar med ett projekt om elevers egna grundantaganden om världen och sådana grundantaganden som de förknippar med naturvetenskapen (Hansson \& Redfors, 2007a, 2006b, 2006c, 2007b). I detta projekt har kosmologi använts som kontext. Den andra författaren arbetar med ett projekt som handlar om elevers intresse för naturvetenskap/teknik och deras val av studieinriktning i gymnasieskolan (Lindahl, 2003). Empirin vi grundar slutsatserna i denna artikel på är hämtad från elevintervjuer under elevernas sista veckor på gymnasiet (se Hansson \& Lindahl, 2007). 
Eleverna vi har intervjuat har följts i en longitudinell studie av en av författarna (Lindahl, 2003) sedan eleverna gick år $5 \mathrm{i}$ grundskolan. De intervjuer vi hämtar empirin till denna artikel från genomfördes under vårterminen 2005 och handlar om skolan, framtiden, naturvetenskapen och världsbild. Vi ställde i detta sammanhang en fråga om huruvida eleverna trodde det var möjligt, samt tyckte det var önskvärt att göra om planeten Mars så att människor skulle kunna bo där i framtiden. Vi har samtalat med 23 elever (en tredjedel pojkar och två tredjedelar flickor) om detta och det är denna del av samtalen som artikeln grundar sig på. Eftersom denna fråga nu blev speciellt aktuell - i och med Fuglesangs rymdresa och hans försök att motivera rymdresor med just detta - har vi här gjort en separat analys av elevernas resonemang kring denna frågeställning, även om detta från början inte var vårt syfte. Intervjuerna har spelats in och vi har sedan analyserat materialet. Analysen har lett fram till de olika synsätt och resonemang som vi presenterar nedan.

\section{RESULTAT}

De synsätt som framkommer vid analysen presenteras här under två huvudrubriker: Negativ inställning till möjligheten/det önskvärda $i$ att genomföra förändringarna av Mars, samt Positiv inställning till att genomföra förändringarna av Mars. Under dessa rubriker beskrivs och exemplifieras elevernas synsätt och resonemang. De flesta av eleverna har en negativ inställning till att göra om Mars och dessa elevers resonemang delas in i två olika typer, beroende på vad resonemanget grundas på. Vi beskriver synsätt, men anger p.g.a för litet urval inga frekvenser. Av samma skäl diskuterar vi inte eventuella skillnader mellan tjejers och killars synsätt. Negativ liksom positiv inställning förekommer dock hos såväl tjejer som killar.

\section{Negativ inställning till möjligheten/det önskvärda i att genomföra förändringarna av Mars}

Som nämnts ovan ser vi två olika typer av resonemang hos de elever som har negativ inställning till möjligheten och/eller det önskvärda i att förändra Mars så att vi människor ska kunna bo där i framtiden. I det första fallet beror den negativa inställningen på konflikter med grundantaganden som är en del av elevens världsbild, medan det i det andra fallet handlar om ideologiska ställningstaganden om hur och på vad vi bör satsa våra resurser. Det finns också elever som använder båda typerna av resonemang. Vi börjar med de elever som ser visionen som problematisk p.g.a deras världsbild.

En del av eleverna menar att det överhuvudtaget inte är möjligt att göra om planeten Mars så att människor kan bo där i framtiden. Man menar t.ex. att naturen är överordnad människan och inte skulle tillåta sådana ingrepp. Ett exempel på en elev som inte tror att förändringarna är möjliga att åstadkomma är Camilla. Hon säger så här:

Camilla: I nuläget tror jag inte det skulle gå.

Intervjuare: $\mathrm{mm}$.

Camilla: men sen utvecklas vi ju mer och mer hela tiden så det är mycket möjligt att de skulle kunna göra en sån sak, men jag tror inte att det skulle hålla.

Intervjuare: Hur tänker du att det inte skulle hålla...

Camilla: Jag tror inte att det skulle funka, jag tror inte man ska mixtra så mycket med naturen. Intervjuare: $\mathrm{mm}$.

Camilla: att man börjar ändra på saker som..., nej. Man skulle nog kunna prova och det skulle funka ett tag men det skulle inte hålla en längre tid.

Intervjuare: Varför tänker du att det inte skulle hålla?

Camilla: För att naturen skulle säga ifrån.

Den här eleven för ett resonemang där naturen inte skulle acceptera att människan försöker gå in och göra denna typ av förändringar. Hennes syn på huruvida man ska göra om planeten Mars så att människor kan bo där i framtiden är alltså grundad i hennes syn på relationen mellan män- 
niskan och naturen - människan är ur hennes synvinkel inte överordnad naturen utan tvärt om. Det är naturen som styr och försöker människan ingripa för mycket, så kommer naturen att slå tillbaka.

Andra elever menar att det kanske skulle vara möjligt, men att det skulle få negativa konsekvenser eller vara etiskt fel av människan att göra sådana ingrepp. De menar att vi människor inte ska ingripa i den naturliga ordningen. En elev som menar att det är etiskt fel är Felicia. Hon resonerar så här:

Felicia: Man kan ju stanna här så länge det går, men kan väl vara en bra idé om det inte går att stanna här [Intervjuare: $\mathrm{mm}$ ] tycker jag, men varför skulle vi komma dit och förändra hela det? Det är väl lite fel, tycker jag.

Intervjuare: Du tycker det är lite fel?

Felicia: Jag tycker att det är lite fel. För det är ju ändå så från början. Det finns något slags skäl till att det inte finns liv där. [Intervjuare: $\mathrm{mm}$ ] Så varför ska vi, vi människor återigen liksom sätta oss emot allting och göra emot det som liksom var från början och ändra om bara för att vi tycker att det är rätt. Det finns så ju så, vi är bara en sån pytteliten del så varför ska just vi ha rätt?

Intervjuare: Du tycker inte att det, det är inte riktigt?

Felicia: Men det skulle nog vara möjligt, det tror jag.

Intervjuare: Tror du att det är möjligt, men du tycker inte det är särskilt lämpligt?

Felicia: Det skulle inte vara etiskt rätt, som moral. Min, ja.

Intervjuare: $\mathrm{mm}$.

Felicia: Det är ungefär som jag tycker det är liksom k... varför man ska...en jättefin skog och så bara kalhugger ner den och lägger värsta asfaltgrejen. Jag tycker det är liksom, fattar inte varför man inte kan låta den vara.

Felicia menar alltså att det är etiskt fel av människan att göra den här typen av ingrepp, även om det skulle vara möjligt. Människan bör inte överordna sig den ursprungliga ordningen på detta sätt.

Bland de elever som liksom Felicia menar att det i och för sig kanske är eller kommer bli möjligt att genomföra sådana förändringar, men inte vill att dessa ska genomföras förekommer också ett annat vanligt argument. Skälet som anges handlar om resurser och hävdas starkt i elevgruppen. Man menar att de pengar som skulle krävas för detta kan satsas på ett annat och enligt dem vettigare sätt - t.ex. på miljöförbättringar här på jorden eller på den fattiga delen av världen. Anja resonerar så här:

Anja: Det har jag för lite kunskap att säga om det är möjligt. Jag har ingen aning om klimat och liksom vad som krävs för och så. Men liksom säger forskarna att det går så är det mycket möjligt att det går rent teoretiskt sätt. Sen vet jag inte om det funkar i praktiken liksom.

/.../

Anja: Men sen tycker jag också att det är lite slöseri med pengar att forska så jättemycket kring det och om man nu ska försöka göra det här projektet. Hur mycket pengar skulle inte det då kosta?

Intervjuare: mycket.

Anja: Ja, det är ofantligt mycket pengar och då tycker jag att man kunde ge alla de pengarna till typ Afrika eller någonting och byggt ut skolor och ett välfärdssystem där i stället. Det är lätt för oss i västvärlden att hålla på om sånt, men jag tror inte att våra grannar i söder riktigt skulle hållt med oss

Intervjuare: $m m$. Så du tycker inte att det är en särskilt bra idé?

Anja: Nej, sen är det ju möjligt att vi måste hitta andra vägar att leva när jorden liksom så.

Intervjuare: $\mathrm{mm}$. 
Anja: men då är det ett problem vi får ta då liksom så.

Intervjuare: så då tycker du att det skulle vara...va en vettig tanke?

Anja: ja liksom det är mycket möjligt att liksom om 500 år så behöver vi det för det kan det kan jag verkligen inte säg nu.

Intervjuare: då har du egentligen inget emot det, alltså så?

Anja: nej, nej, är det någonting vi..Men som sagt jag tror att om vi löser våra egna problem här.

Intervjuare: $\mathrm{mm}$.

Anja: ser till så att vi inte förorenar vår jord först innan vi funderar på att flytta till Mars, så skulle det vara mycket bättre.

/.../

Oviljan inför projektet att göra om Mars till en planet som vi kan bo på är för Anja grundat i en ideologisk syn på vad vi ska satsa resurser på. Hon tycks inte dela inte den modernistiska och teknikpositiva ideologi som visionen bygger på.

\section{Positiv inställning till att genomföra förändringarna av Mars}

Hittills har vi sett exempel på elever som på olika grunder är skeptiska till Fuglesangs vision. Finns det då några som delar denna? Jo, ett fåtal av eleverna tycker att det är en bra idé att förändra Mars så att vi människor kan bo där i framtiden. Kent resonerar så här:

Kent: Ja, alltså varför inte? Man vet ju aldrig vad folk kan göra.

Intervjuare: $\mathrm{mm}$.

Kent: alltså det låter ju helt otroligt, men man vet ju aldrig.

Intervjuare: nej okey, tycker du det verkar som en bra idé liksom? Alltså skulle du, är det någonting som du tycker skulle vara lämpligt och fortsätta med?

Kent: Varför inte? Alltså man vet ju aldrig vad som händer med jorden.

Intervjuare: nej.

Kent: sen ja...det kan vara bra att ha en "back-up plan" .

Dessa elever delar Fuglesangs vision.

\section{DISKUSSION OCH SLUTSATS}

För Fuglesang tycks det vara självklart att det är något önskvärt att göra om Mars till en planet som vi människor kan leva på i framtiden. För honom ligger det inget problematiskt i den tanken. Med samma självklarhet som han diskuterar frågan svarar många av eleverna. Detta är ingen fråga som vanligen diskuteras i samhället (i motsats till t.ex. kärnkraft eller genteknik), men - eller kanske just därför - är svaret självklart för många elever. Detta innebär dock inte att de olika eleverna resonerar på samma sätt, eller delar Fuglesangs värderingar. Den självklarhet som finns i svaren och den omedvetenhet som tycks finnas om andra möjliga synsätt än det egna är ett exempel på svårigheten att gå utanför sin världsbild. Vårt tänkande är i grunden präglad av denna och det krävs något speciellt - t.ex. en diskussion med andra som inte delar vår bild - för att vi ska bli medveten om den.

För de få elever som uttrycker sig positivt i förhållande till visionen om att människor så småningom skulle kunna bo på Mars kanske Fuglesangs försök att övertyga om vitsen med rymdresor lyckas. Man kan också tro att en diskurs som den som presenterades i det inledande citatet i artikeln skulle kunna leda till att dessa elever får ett ökat intresse för naturvetenskap/teknik, så som bl.a. regeringen hoppas på. För övriga elever är det inte troligt att de kommer attraheras av en sådan diskurs. För vissa av eleverna blir Fuglesangs vision problematisk p.g.a. en världsbild där naturen är överordnad människan, för andra p.g.a. en ideologi där man menar att resurserna bör satsas på annat som t.ex. förbättringar av miljön på jorden eller förbättringar för människor i u-länder. 
Vad som är intressant och som vi vill lyfta fram är huvudsakligen inte vad eleverna tycker i just denna fråga - även om det i sig självt också kan vara intressant. I stället vill vi belysa hur viktigt det är att naturvetenskapen syns tillsammans med olika typer av ideologier. Vi har här sett ett exempel, där naturvetenskapen förekommer tillsammans med en teknikpositiv, modernistisk diskurs. Vi har också sett många elevers skeptiska hållning till visionen. Något som man trodde var ett sätt att övertyga och skapa intresse, kanske fick motsatt verkan för många. Detta understryker vikten av det Stenmark (2004) skriver:

"We need a scientific education which contains a study of examples of worldview influences on past and present scientific research, so that scientists can develop a better and less naïve understanding of how their own and other people's ideological or religious commitments interact with scientific practice at different levels" (s. 249)

Naturvetenskapen måste synas i samband med många olika ideologiska utgångspunkter, så att ungdomar med olika ideologier och världsbilder kan identifiera sig med naturvetenskapen. Om vi inte lyckas med detta, är det stor risk att vi får en exkludering av individer såväl som av ideologier/ världsbilder på olika nivåer i utbildningssystemet.

\section{REFERENSER}

Brickhouse, N.W. (2001). Embodying Science: A Feminist Perspective on Learning, Journal of Research in Science Teaching, 38(3), 282-295.

Cobern, W.W. (1991). World view theory and science education research. NARST Monograph No. 3. Manhattan, KS: National Association for Research in Science Teaching.

Cobern, W. W. (1996). Worldview Theory and Conceptual Change in Science Education, Science Education, 80(5), 579-610.

EU (2004). Europe needs more scientists. Report by the High Level Group on Increasing Human Resources on Science and Technology in Europe. Retrieved 2007-02-22 from http://ec.europa. eu/research/conferences/2004/sciprof/pdf/final_en.pdf

EU (2005). Science and Society Portal of the European Commision. Retrieved 2007-02-22 from http://ec.europa.eu/research/conferences/2004/sciprof/pdf/final_en.pdf

Fourez, G. (1988). Ideologies and Science Teaching. Bulletin of Science, Technology \& Society 8, 269-277.

Hansson, L. \& Lindahl, B. (2007 - manuskript). Students' presuppositions of what the world is like and their interest in choosing a science profile in their studies.

Hansson, L. \& Redfors A. (2006a). Swedish Upper Secondary Students' Views of the Origin and Development of the Universe. Research in Science Education 36, 355-379.

Hansson, L. \& Redfors, A. (2006b). Tre elever berättar om universum, gud och fysiken. Nordina 1/06, 31-43.

Hansson, L. \& Redfors, A. (2007a). Physics and the Possibility of a Religious View of the Universe: Swedish Upper Secondary Students' Views. Science \& Education, 16, 461-478. Publicerad OnlineFirst 2006.

Hansson, L. \& Redfors A. (2007b). Upper secondary students in group discussions about physics and our presuppositions of the world. Science \& Education (publiserad OnlineFirst 2006).

Lemke, J.L. (2001). Articulating Communities: Sociocultural Perspectives on Science Education, Journal of Research in Science Teaching, 38(3), 296-316.

Lindahl, B. (2003). Lust att lära naturvetenskap och teknik? En longitudinell studie om vägen till gymnasiet. (Diss., Göteborg studies in educational sciences 196), Göteborg: Acta Universitatis Gothoburgensis.

Lyons, T. (2006). Different countries same science classes: students' experiences of school science in their own words. International Journal of Science Education, 28(6), 591-613 
Roberts, D. A. (1998). Analysing School Science Courses: The Concept of Companion Meaning. I D.A. Roberts and L. Östman (Red.). Problems of Meaning in Science Curriculum (s. 5-12). Teacher College Press, New York.

Stenmark, M. (2004). How to Relate Science and Religion - a multidimensional model. William B. Eerdmans Publishing Company Grand Rapids, Michigan, Cambridge, U.K.

Svt - intervju med Christer Fuglesang i svt:s "Aktuellt" 25/1-07 http://svt.se/svt/play/video. $\mathrm{jsp} ? \mathrm{a}=746807$

Östman, L. (1995). Socialisation och mening. No-utbildning som politiskt och miljömoraliskt problem. Acta Universitatis Upsaliensis. Uppsala Studies in Education 61. 